\title{
Letter to Editor: Telerehabilitation: A Useful and appropriate approach for people with disability in Covid-19 pandemic
}

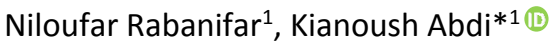 \\ Received: 22 Nov 2020 \\ Published: 4 Feb 2021 \\ Conflicts of Interest: None declared \\ Funding: None \\ *This work has been published under CC BY-NC-SA 1.0 license. \\ Copyright $\odot$ Iran University of Medical Sciences
}

Cite this article as: Rabanifar N, Abdi K. Letter to Editor: Telerehabilitation: A Useful and appropriate approach for people with disability in Covid19 pandemic. Med J Islam Repub Iran. 2021 (4 Feb);35:18. https://doi.org/10.47176/mjiri.35.18

\section{Dear Editor}

Coronavirus disease (COVID-19) is an infectious disease caused by a newly discovered coronavirus. The disease was announced a worldwide pandemic by the World Health Organization on March 11, 2019, and there are about 66 million confirmed cases and 1.5 million deaths in 220 countries and regions (December 7, 2020) (1).

The pandemic not only affects the financial and social life of people, but also changes the traditional way of managing patients (2). This pandemic requires changing the day-to-day operation of health care systems to increase their flexibility. The number of outpatient visits has decreased due to the increasing spread of the virus (3). To prevent the transmission of the disease, social distancing is recommended as the best strategy and staying at home and avoiding outdoor activities are also highly suggested. On the other hand, people with disabilities often need rehabilitation interventions such as physiotherapy, occupational therapy, speech therapy, and behavioral therapy (4). Thus, access to rehabilitation services for people with disabilities has been limited. Moreover, to minimize the risk of the spread of the virus, limitations on social life have reduced the level of physical activity of individuals (5).

Pandemics always cause particular challenges to health care delivery. As the number of patients grows exponentially at the time of pandemics, health care services decline at the same rate.

In such a condition, telemedicine can be an effective way to rationally allocate medical resources. The benefits of telemedicine have been documented in these conditions $(6,7)$.

Telerehabilitation is related to telemedicine, but there are some differences between them. The most important difference is that telerehabilitation requires particular technologies beyond audiovisual communication (8). Telerehabilitation specifically refers to the provision of rehabilitation services through telemedicine methods and techniques (9). Fortunately, advances in robotics and communication and information processing can simplify remote services (8). Remote care refers to specific cases in which health or care services are provided to individuals in their homes or other supervised living centers (9). Whereas in the traditional clinic and hospital-based rehabilitation programs, one has to waste time and money to receive services and attend the centers (10). Furthermore, these operation systems are ideal for managing several challenges of health care systems during global infectious disease outbreaks. Implementing them not only eliminates the patients' need for rehabilitation but also alleviates their worries about attending crowded centers, such as hospitals and clinical wards, which may result in more exposure to the disease. This is especially more important in areas with limited resources (11).

Telerehabilitation services can even use a variety of video communication tools, many of them are free or lowcost, including Apple Face Time, Facebook Messenger video chat, Google Hangouts video, and Skype. Thus, with these applications, the patient will only need a mobile phone, a tablet, a computer and an internet connection to communicate with the specialist (12).

Therefore, in the current situation where the corona virus disease affects millions of people around the world and the need for social distancing is highly recommended as a new policy and people with disabilities are at a higher risk, especially those with defective immune systems such as multiple sclerosis and Parkinson's disease, telerehabilitation can be the best and only option for providing reha- 
bilitation services to them. Nowadays, with advances in robotics and remote technologies, telerehabilitation can be conveniently accessible for everyone and everywhere.

It is noteworthy to mention that like every technology, telerehabilitation has some disadvantages and limitation. In terms of disadvantages, the main drawback is loss of face-to-face meeting and human contact with the clinician. Moreover, telerehabilitation is not reliable or doable for some physical assessment like lumbar spine posture, orthopedic special tests, and scar evaluation (13-15). In terms of limitation, difficult access and costs for providing rehabilitation services are main barriers. Furthermore, providers, recipients, the society should become ready to use telerehabilitation, and for this purpose comprehensive studies and some training for people are needed (10).

\section{Conflict of Interests}

The authors declare that they have no competing interests.

\section{References}

1. https://www.who.int/emergencies/diseases/novel-coronavirus-2019.

2. Surya N, Someshwar H, Patil B, Sharma D, Sharma A, Kardile M, Someshwar J." Comprehensive Epilepsy care during the lockdown due to COVID-19 Pandemic in INDIA "Epilepsy Foundation India Model.” Int J Curr Res. 2020;12 (07):12159-12162

3. Fioratti I, Fernandes LG, Reis FJ, Saragiotto BT. Strategies for a safe and assertive telerehabilitation practice. Braz J Phys Ther. 2020.

4. Dhiman S, Sahu PK, Reed WR, Ganesh GS, Goyal RK, Jain S. Impact of COVID-19 outbreak on mental health and perceived strain among caregivers tending children with special needs. Dev Disabil Res Rev. 2020:103790.

5. Kahraman T. Koronavirüs Hastalığı (COVID-19) Pandemisi ve Telerehabilitasyon. İzmir Katip Çelebi Üniversitesi Sağlık Bilimleri Fakültesi Dergisi. 2020;5(2):87-92.

6. Hong Z, Li N, Li D, Li J, Li B, Xiong W, et al. Telemedicine During the COVID-19 Pandemic: Experiences from Western China. J Med Internet Res. 2020;22(5): e19577.

7. Lurie N, Carr BG. The Role of Telehealth in the Medical Response to Disasters. JAMA Intern Med. 2018;178(6):745-6.

8. Carignan CR, Krebs HI. Telerehabilitation robotics: bright lights, big future? J Exerc Rehabil. 2006;43(5):695.

9. Brennan DM, Mawson S, Brownsell S. Telerehabilitation: enabling the remote delivery of healthcare, rehabilitation, and self-management. Stud Health Technol Inform. 2009;145(231):48.

10. Rabanifar N, Abdi K. Rehabilitation Services: Why Should We Use Tele-Rehabilitation in Iran? Necessity and Application. Iran Rehabil J. 2019;17(4):293-6.

11. Rockwell KL, Gilroy AS. Incorporating telemedicine as part of COVID-19 outbreak response systems. Am J Manag Care. 2020;26(4):147-8.

12. Calton B, Abedini N, Fratkin M. Telemedicine in the time of coronavirus. J Pain Symptom Manage. 2020.

13. Peretti A, Amenta F, Tayebati SK, Nittari G, Mahdi SS. Telerehabilitation: Review of the State-of-the-Art and Areas of Application. JMIR Rehabil Assist Technol. 2017;4(2):e7.

14. Mani S, Sharma S, Omar B, Paungmali A, Joseph L. Validity and reliability of Internet-based physiotherapy assessment for musculoskeletal disorders: a systematic review. J Telemed Telecare. 2017 Apr;23(3):379-391.

15. Holst A, Nejati S, Björkelund C, Eriksson MC, Hange D, Kivi M, Wikberg C, Petersson EL. Patients' experiences of a computerised self-help program for treating depression - a qualitative study of Internet mediated cognitive behavioural therapy in primary care. Scand J Prim Health Care. 2017 Mar;35(1):46-53. 